\title{
EDUCATIONAL TOOLKIT BASED ON DESIGN METHODOLOGIES TO PROMOTE SCIENTIFIC KNOWLEDGE TRANSFER IN SECONDARY SCHOOLS: A GRAPHENE-CENTERED CASE STUDY
}

\author{
Blanca Guasch ${ }^{1}$ (D) Marta González ${ }^{1}$, Sergi Cortiñas ${ }^{2}$ (D) \\ ${ }^{1}$ Elisava Barcelona School of Design and Engineering (Spain) \\ ${ }^{2}$ Universitat Pompeu Fabra (Spain) \\ bguascbba@elisava.net,mgonzalez@elisava.net,sergi.cortinas@upf.edu
}

Received July 2019

Accepted September 2019

\section{Abstract}

Nanoscience and nanotechnology are two key areas in the development of new technologies. However, scientific advances in these fields are still far removed from the contents taught in schools. But what if basic concepts within these areas were introduced in secondary schools? We believe science is an essential facet of culture and the most recent scientific advances should be within everyone's reach. With this in mind, we have developed and tested an educational toolkit to transfer complex scientific concepts in classrooms. The toolkit is based on design and creative thinking methodologies, and graphene is used as an example of a subject that is challenging to communicate within the area of nanoscience. This paper highlights the development of the toolkit and it being tested out in a secondary school by 93 students between the ages of 11 and 13. The testing was carried out through the creation of a workshop called "Graphene in the Classroom." We determined five evaluation categories: Acquiring Knowledge, Satisfaction, Challenges, Teamwork, and Facilitator's Role. The results show that integrating scientific content and design methodologies is a complex yet profitable strategy. The toolkit demonstrated to allow the translation of a complex language into friendlier, more approachable, and easier language. The classroom climate was positive and the presence of a facilitator enhanced motivation, empathy, scientific rigor, and adequate adaptation of contents.

Keywords - Educational toolkit, graphene, nanotechnology, knowledge transfer, design methodologies, science education.

\section{To cite this article:}

Guasch, B., González, M. \& Cortiñas, S. (2020). Educational toolkit based on design methodologies to promote scientific knowledge transfer in secondary schools: a graphene-centered case study. Journal of Technology and Science Education, 10(1), 17-31. https://doi.org/10.3926/jotse.787

\section{Introduction}

Nanoscience and nanotechnology are two emerging fields that are gaining ground on the market every day (Correia \& Serena-Domingo, 2010; Hirsch, 2015). Everything appears to indicate that they will be two key areas for the development of new technologies and applications in the future. That said, knowledge of 
them is still clustered within specialized scientific fields. However, what would happen if basic terms and concepts from these areas began to be introduced in secondary schools?

For our research, we developed a toolkit to transfer scientific knowledge in secondary schools about a nanomaterial: graphene (Mertens, 2018; Novoselov, Geim, Morozov, Jiang, Zhang, Dubonos et al., 2004). The aim of the toolkit was to set the stage for a dynamic activity based on creative thinking to transfer basic knowledge about graphene, which could serve as a starting point for introducing nanoscience and nanotechnology in schools. Creative thinking and design methodologies served as an inspiration for the creation of the experimental teaching materials included in the toolkit. To test this toolkit, a workshop was held with three groups of 30 to 32 students in the first year of secondary school - a total of 93 students between the ages of 11 and 13. The workshop was called "Graphene in the Classroom."

The vision of interconnection and complementarity between disciplines that this project aimed to convey was quite in line with the idea of STEM education. We believe that carrying out dynamic activities like those described in this paper facilitates the promotion of scientific and technological careers for children and teenagers in a fun and clear manner. The project also intended to share the idea that nanoscience and nanotechnology are fields of study that can be accessed from many approaches and areas, such as the world of design.

The relevance of this paper lies in the notion that the field of design can create a new learning environment for science for secondary school students.

\section{Background}

\subsection{Schools and Classrooms as Learning Environments}

Schools, especially classrooms, are social organizations based on learning. However, although learning is the central focus, a specific emotional atmosphere is created within each classroom that also affects a student's personal growth (Carroll, Goldman, Britos \& Koh, 2010; Scheer, Noweski \& Meinel, 2012). This climate depends greatly on the teacher's attitude, as well as the resources that are used and the activities that take place therein.

The quality of the atmosphere or climate created in the classroom is highly relevant as, in many cases, it depends on student motivation and discipline (Hugerat, 2016). These two aspects can greatly impact academic performance and, given the number of hours a student spends in school, this is a key point in the field of education. Some authors have defined the benefits of a good climate in the classroom. Among them, they emphasize interest in the subjects, acquiring and using knowledge, learning through trial and error, self-confidence, and accepting mistakes (Broussard \& Garrison, 2004).

\subsection{Scientific Projects in the Classroom}

Undertaking scientific projects in schools usually involves a change in the setup of the classroom or a change of location - if the school has a science laboratory. Reorganizing the classroom and/or changing locations can directly affect student behavior in class as well as their relationship with their surroundings and their classmates (Hugerat, 2016). It has been shown that a flexible work environment facilitates student-centered education, collaboration, self-regulation, autonomy, motivation, inclusion, and interaction (Kariippanon, Cliff, Lancaster, Okely \& Parrish, 2018; Valdez \& Bungihan, 2019).

Therefore, science education in schools not only allows students to discover and understand scientific facts and principles, but also, and in large part, to stimulate positive behavior, adopt new ways of thinking, satisfy curiosities, promote conflict resolution, enhance skills, practice critical thinking, and increase self-confidence, among others (Hadim \& Esche, 2002). In fact, Dewey (1902) asserts that the most natural way for children to learn is by doing. However, he also states that children should be guided in this process and they must be provided with the necessary tools and activities to acquire knowledge.

\subsection{Design as a Tool for Science Education}

The variety of formats that scientific activities can employ is an opportunity for teachers to experiment with new resources and dynamics. Particularly, student-centered activities are highly relevant in science 
education (Pratt, 2002). This approach allows students to satisfy their learning needs, be guided, receive feedback, be stimulated, to empathize with them, and foster mutual trust and respect (Pratt, 2002).

In the field of design, there are tools that seek the same objectives, with a purely social focus (Sanders \& Stappers, 2008). Creative thinking, or Design Thinking, is a technique that is based on exploring different fields and possibilities with the aim of producing strategies to address a problem or a challenge (Curedale, 2016; Design United, 2013; Hanington \& Martin, 2012; Leblanc, 2016). Its operating engine is lateral thinking (de Bono, 1994) which aims to address a challenge or a problem from very different, wide, and complementary views instead of taking the most logical solution as the only option. Lateral thinking and all Design Thinking methodologies enable designers in their day-to-day work to search for new solutions in the form of products, systems, and services in a constantly changing and evolving world. Multiple authors have defined its characteristics, phases, and benefits (Carroll et al., 2010; Dorst, 2011; Scheer et al., 2012).

Design methodologies can be applied across a multitude of formats. However, regardless of the format, they always seek to gain access to two types of knowledge. On the one hand, participants' tacit knowledge, that is, what they know but cannot express. On the other hand, practical knowledge, that is, what participants know how to do based on previously experienced situations (Spinuzzi, 2005). The combination of these two forms of knowledge lends understanding, motivation, attention, creativity, and interest to the subject being studied (Guasch, Cortiñas, González \& Peña, 2019).

In a way, activities based on creative thinking are related to project-based education (Hadim \& Esche, 2002; Scheer et al., 2012). In both cases, students usually work in groups and the activities are focused on helping participants build their own knowledge. However, when we discuss applying design methodologies to co-design activities, we are not referring to projects or classes, but workshops. Likewise, the person who leads and moderates an activity is not called a teacher or an instructor, but a facilitator (Sanders \& Stappers, 2008). A facilitator is the person who plans and designs a creative workshop, taking into account the objectives, methodology, time spent on each part, focus, and characteristics of the participants (Raijmakers, Thompson \& Van de Garde-Perik, 2012). The facilitator also guides and leads the activity, prepares the necessary materials, adequately adapts the space, and encourages participants to express themselves freely in the workshop (Sanders \& Stappers, 2008). Students who feel a facilitator's support and presence tend to be more motivated and make greater efforts to reach a goal (Lumpkin, 2007).

In these types of activities, participants often find themselves disoriented at first as they are given much more freedom to work with compared to traditional learning methods (Hugerat, 2016). However, this freedom also allows them to abandon the habit of following the teacher's direct instructions in order to explore new ways of learning and to create their own work pace (Lenschow, 1998). Table 1 shows a brief description of the design methodologies that were used in carrying out this research (Dignan, 2011; Hanington \& Martin, 2012). In most of them, the use of concept maps as a learning and working strategy is a common characteristic (Romero, Cazorla \& Buzón, 2017).

\begin{tabular}{|l|l|}
\hline \multicolumn{1}{|c|}{ Methodology } & \multicolumn{1}{c|}{ Description } \\
\hline Cognitive mapping & $\begin{array}{l}\text { Visualization of how participants give meaning to a particular topic. It usually takes the form } \\
\text { of an outline or structured text that contains essential ideas. }\end{array}$ \\
\hline Gamification & $\begin{array}{l}\text { The application of games in non-game contexts. The creation or use of a game in an } \\
\text { educational setting is gamification. }\end{array}$ \\
\hline $\begin{array}{l}\text { Mental model } \\
\text { diagram }\end{array}$ & $\begin{array}{l}\text { Diagram or outline that aids in expressing causes and effects or other dualities, such as related } \\
\text { properties and applications. It is used to find a relationship between items that are part of two } \\
\text { different but complementary realities. }\end{array}$ \\
\hline Collage & $\begin{array}{l}\text { This technique allows participants to express thoughts, ideas, and/or concepts visually. It } \\
\text { always involves a board and stickers or other items that can be placed freely on the board. }\end{array}$ \\
\hline $\begin{array}{l}\text { Participatory } \\
\text { design }\end{array}$ & $\begin{array}{l}\text { This approach is centered on society and the individual, which fosters the active involvement } \\
\text { of participants in a cooperative activity. It is an approach and a way of working rather than a } \\
\text { technique. }\end{array}$ \\
\hline
\end{tabular}




\begin{tabular}{|l|l|}
\hline \multicolumn{1}{|c|}{ Methodology } & \multicolumn{1}{c|}{ Description } \\
\hline $\begin{array}{l}\text { Research through } \\
\text { design }\end{array}$ & $\begin{array}{l}\text { This method involves examining design tools and processes in order to apply them to other } \\
\text { areas. It is used to acquire knowledge about a topic through designing a product or system. }\end{array}$ \\
\hline Concept mapping & $\begin{array}{l}\text { This is a visual technique that enables participants to digest new concepts and give them new } \\
\text { meaning. It uses the information to organize it differently while giving it new meaning. It is } \\
\text { used to enhance recall of concepts learned beforehand. }\end{array}$ \\
\hline $\begin{array}{l}\text { Evaluative } \\
\text { research }\end{array}$ & $\begin{array}{l}\text { This involves the testing of prototypes, products, or interfaces by potential future users. } \\
\text { Interaction between a design and participants to contribute their opinions. }\end{array}$ \\
\hline $\begin{array}{l}\text { Fly-on-the-wall } \\
\text { observation }\end{array}$ & $\begin{array}{l}\text { This observation technique allows researchers to gather information in a non-invasive manner. } \\
\text { A researcher compiles information while watching and listening to an activity's participants, } \\
\text { not interfering with their work. }\end{array}$ \\
\hline
\end{tabular}

Table 1. Description of the design methodologies used in the project

\subsection{Nanoscience, Nanotechnology, and Graphene}

Nanoscience and nanotechnology are revolutionizing industry and becoming increasingly visible in our surroundings to such an extent that experts say that companies that adapt and understand how to make good use of nanotechnologies will be at the forefront of industry in coming years (Correia \& Serena-Domingo, 2010; European Commission, 2012). Graphene is the material that is currently at the forefront of materials science and nanotechnology (Hirsch, 2015). For this reason, we considered it to be an interesting, current, and, at present, rarely covered topic in schools.

Graphene is a two-dimensional material consisting of a single layer of carbon atoms bonded together forming a hexagonal lattice (Mertens, 2018). It was isolated for the first time at the University of Manchester in 2004 (Novoselov et al., 2004), and its discoverers won the Nobel Prize in Physics for their discovery in 2010. The material is relevant mainly due to its unique properties. It is more resistant than steel, more conductive than copper, and harder than diamond (Mertens, 2018). Furthermore, it is flexible, transparent, and impermeable even to gas and can be applied to the electronics, transport, medicine, energy, architecture, and other sectors (Ferrari, Bonaccorso, Falko, Novoselov, Roche, Bøggild et al., 2015). Many call it "the wonder material" and, since 2004, technology centers specializing in graphene have been created around the world (Hirsch, 2015).

\section{Objectives}

The main goal of this project was to create an experimental educational toolkit based on design methodologies to transmit scientific knowledge in high schools. It was essential for the toolkit to design work tools that were appropriate and attractive for youth around 12 years of age. In order to test it, we developed the workshop called "Graphene in the Classroom", which had the following objectives:

1) Acquiring Knowledge: The primary objective of the "Graphene in the Classroom" educational initiative was to introduce basic concepts regarding graphene to students in the 1 st year of secondary school, as well as to raise awareness about graphene's importance in the world of materials.

2) Satisfaction: A second objective was to motivate students and generate a positive classroom climate. The workshop and the toolkit sought to promote interest in scientific and technological disciplines to students. They also sought to update secondary school teachers' knowledge, thus boosting their professional qualifications - both in terms of knowledge about graphene and regarding the methodologies used in classrooms to impart scientific topics.

3) Challenges: The third objective was to reduce the complexity usually associated to science. The main goal of the tools and dynamics included in the toolkit was to make graphene understandable for 12-year-old students.

4) Teamwork: Another objective was to maintain a balance between competition and cooperation among students. 
5) Facilitator's Role: The last objective was to test the role of the facilitator. The facilitator had to enhance motivation, transmit empathy, explain clearly, solve doubts, and connect with the students.

\section{Methodology}

\subsection{Generic Toolkit}

The toolkit included five parts (Table 2). Each of them had a name, its duration, up to three methodologies associated, and the materials needed.

\begin{tabular}{|c|c|c|c|c|}
\hline Part & Name & Duration & Methodologies used & Materials \\
\hline$a$ & $\begin{array}{l}\text { Listen and } \\
\text { Understand }\end{array}$ & 30 min. & $\begin{array}{l}\cdot \text { Traditional lesson } \\
\cdot \text { Cognitive mapping }\end{array}$ & Presentation, map, and markers \\
\hline$b$ & Memorize & 20 min. & \multirow{2}{*}{$\begin{array}{l}\cdot \text { Gamification } \\
\cdot \text { Mental model diagram } \\
\cdot \text { Collage }\end{array}$} & $\begin{array}{l}\text { "Memory" cards, explanatory booklets, } \\
\text { yellow and blue labels, markers, and map }\end{array}$ \\
\hline$c$ & $\begin{array}{l}\text { Transfer and } \\
\text { Guess }\end{array}$ & $20 \mathrm{~min}$. & & $\begin{array}{c}\text { Chalk and board, "Pictionary" cards, } \\
\text { explanatory booklets, yellow and blue } \\
\text { labels, markers, and map }\end{array}$ \\
\hline$d$ & Formulate & 20 min. & $\begin{array}{l}\cdot \text { Participatory design } \\
\cdot \text { Research through design } \\
\cdot \text { Concept mapping }\end{array}$ & Map and markers \\
\hline$e$ & $\begin{array}{l}\text { Explain and } \\
\text { Assess }\end{array}$ & 20 min. & - Evaluative research & Map \\
\hline- & - & $\begin{array}{c}\text { Entire } \\
\text { workshop }\end{array}$ & - Fly-on-the-wall observation & Camera, notebook, and pen \\
\hline
\end{tabular}

Table 2. Educational toolkit based on design methodologies to promote scientific knowledge transfer in secondary schools

In the following sections, the case study will help define the parts, methodologies and materials of the toolkit more accurately.

\subsection{Case study: Application of the Toolkit}

The "Graphene in the Classroom" workshop was designed as a dynamic interdisciplinary session that included contents related to graphene and the methodologies from the field of design included in the toolkit. The workshop was held with a total of 93 students between 11 and 13 years of age, divided into three classrooms: A (30 students, 16 girls and 14 boys), B (32 students, 16 girls and 16 boys), and C (31 students, 18 girls and 13 boys). Since the groups were quite large, each class was divided into three subgroups of about 10 or 11 students. A facilitator guided the sessions, aided by three teachers with science and technology backgrounds. Figure 1 shows the tools and materials created for the workshop.

The first part, called Listen and Understand, used a traditional classroom format. In this part, the facilitator explained what graphene is, its main properties, and its sectors of application. This activity aimed to engage students through questions that were brought up throughout the presentation. To assess whether they understood the essential details, they had to compose four sentences about graphene after the explanation on a map (method: cognitive mapping). Then, this map became the focal point of the other activities. Since the map was used as a recurring point for all the activities, it also served as a journal and a record for the session.

The second part of the session, Memorize, was based on the board game called "Memory" (method: gamification). 18 cards were distributed, with nine pairs of two matching cards. Each card in the game contained a property and an application of graphene, related to one another. The students had to place the cards upside down on the table, forming a grid. They took turns picking up pairs of cards until they got a match. Once all the cards had been turned over and matched, each participant received a small booklet with an explanation of the properties and applications that they acquired. Next, they had to draw the property and the application from each card they obtained on separate labels. Properties were put on 
yellow labels and applications were put on blue labels. Next, they placed these labels on the map within the corresponding boxes for properties and applications (methods: mental model diagram and collage). While they did so, they had to explain the properties and applications they obtained to the other students in their group.
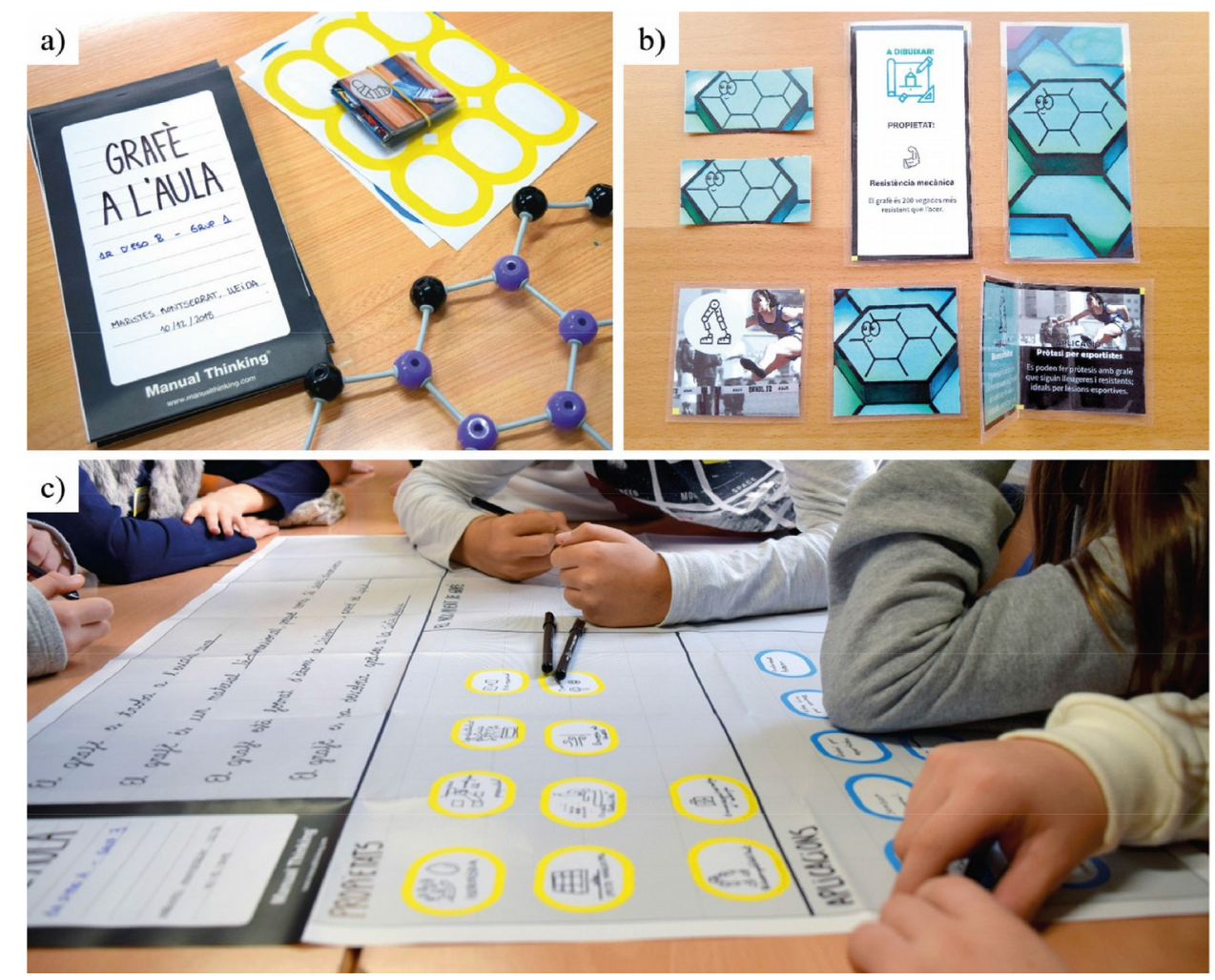

Figure 1. "Graphene in the Classroom" Workshop Toolkit: (a) maps, labels, and stacked cards; (b) "Memory" and "Pictionary" images, cards, and booklets; (c) spread out map

The third part, Transfer and Guess, was also based on a board game, "Pictionary" (method: gamification). In turns, a student from each group went in front of the class, picked up a card with the name of a property, and drew the property on the board. The group that guessed correctly the name of the property kept the explanatory booklet for that property and a related application and had to draw the two items in the blue and yellow labels from the earlier Memorize activity. These labels were added to the map in the corresponding boxes (methods: mental model diagram and collage).

The fourth part of the session, Formulate, called on participants to imagine and invent a new application for graphene (method: participatory design). Together, they had to create a new product by drawing it on the map, in the box called "The latest graphene invention." While drawing this new invention, they addressed doubts by asking the facilitator questions to move the design forward (method: research through design). Additionally, they were asked to explain, using arrows, the product's main characteristics as well as the most relevant reasons why it was important to use graphene for it (method: concept mapping).

Finally, the fifth part, called Explain and Assess, summed up the session. Each group went in front of the class and explained their new graphene application. The other groups had to evaluate the design and its pros and cons (method: evaluative research). Following that, the facilitator asked them what they liked most about the session, what they found most difficult, and their thoughts regarding graphene.

The final methodology used in the workshop was not associated with any particular part, but with all of them. It is called fly-on-the-wall observation. Throughout the session, the facilitator and the teachers present were responsible for taking photographs and notes of the session and student comments. 
Figure 2 illustrates how the toolkit was used in every part of the workshop.

a) Listen and Understand

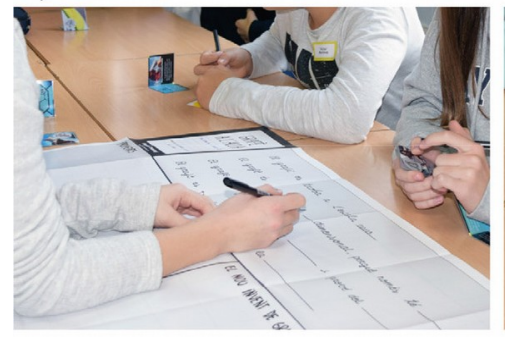

d) Formulate

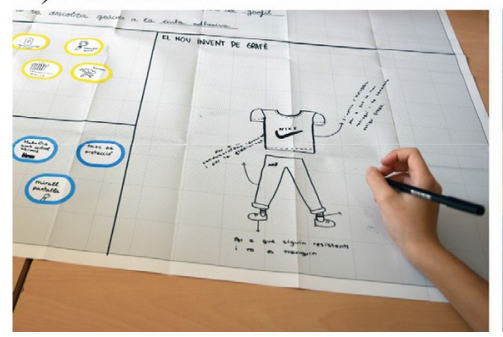

b) Memorize

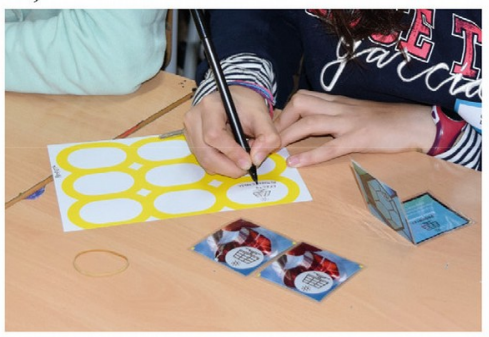

e) Explain and Assess

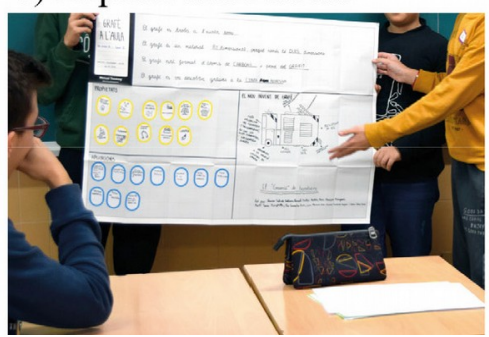

c) Transfer and Guess

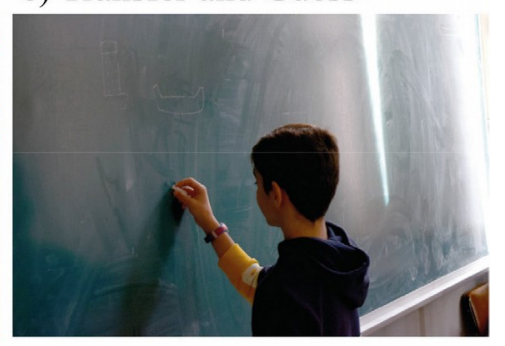

Figure 2. Photos of the workshop "Graphene in the Classroom."

\subsection{Workshop Assessment Tools}

The workshop's main assessment tool was a questionnaire that evaluated and compiled the students' views regarding the activity. The following categories were established for the questionnaire: Acquiring Knowledge, Satisfaction, Challenges, Teamwork, and the Facilitator's Role (Table 3), according to the five objectives of the study. There were 35 questions in total, all of them closedended. The students had to indicate if they agreed, somewhat agreed, somewhat disagreed, or disagreed with the statements used. Some statements were framed negatively to prevent students from giving automatic responses.

\begin{tabular}{|c|c|c|}
\hline Category & & Statements to evaluate \\
\hline $\begin{array}{l}\text { C1. } \\
\text { Acquiring } \\
\text { Knowledge }\end{array}$ & $\begin{array}{l}\text { C1.S1 } \\
\text { C1.S2 } \\
\text { C1.S3 } \\
\text { C1.S4 } \\
\text { C1.S5 } \\
\text { C1.S6 } \\
\text { C1.S7 }\end{array}$ & $\begin{array}{l}\text { The workshop was interesting and useful. } \\
\text { I learned a lot about graphene and nanomaterials. } \\
\text { Some concepts were not clear during session. } \\
\text { I still remember most of the things we learned. } \\
\text { I am satisfied that I understood the information presented in the workshop. } \\
\text { Working on a team motivated me to learn. } \\
\text { The facilitator did not adapt the information to our level. }\end{array}$ \\
\hline $\begin{array}{l}\text { C2. } \\
\text { Satisfaction }\end{array}$ & $\begin{array}{l}\text { C2.S1 } \\
\text { C2.S2 } \\
\text { C2.S3 } \\
\text { C2.S4 } \\
\text { C2.S5 } \\
\text { C2.S6 } \\
\text { C2.S7 }\end{array}$ & $\begin{array}{l}\text { The activities were fun and engaging. } \\
\text { I am satisfied with my participation in the activity. } \\
\text { The facilitator was satisfied with my work. } \\
\text { I enjoyed the different activities that were presented to us. } \\
\text { I felt that I was able to work with complex concepts during the workshop. } \\
\text { I liked the workshop format and I enjoyed it more than a normal class. } \\
\text { The activity lasting for two hours seemed too long. }\end{array}$ \\
\hline $\begin{array}{l}\text { C3. } \\
\text { Challenges }\end{array}$ & $\begin{array}{l}\text { C3.S1 } \\
\text { C3.S2 } \\
\text { C3.S3 } \\
\text { C3.S4 } \\
\text { C3.S5 } \\
\text { C3.S6 } \\
\text { C3.S7 }\end{array}$ & $\begin{array}{l}\text { I thought the content was too challenging for my level. } \\
\text { I felt there was gender discrimination during the session. } \\
\text { The workshop tasks were very difficult. } \\
\text { I was uneasy during the workshop because I'm not used to this kind of activity. } \\
\text { It was hard to understand what the facilitator wanted from us at certain times. } \\
\text { The activities had too many rules and it was difficult to follow them. } \\
\text { I felt lost during the workshop because I had too much freedom while working. }\end{array}$ \\
\hline
\end{tabular}




\begin{tabular}{|l|ll|}
\hline \multicolumn{1}{|c|}{ Category } & \multicolumn{2}{c|}{ Statements to evaluate } \\
\hline \multirow{4}{*}{ C4. } & C4.S1 & I got along well with the other members in my group. \\
Teamwork & C4.S2 & Some of my group's member didn't want to participate in the activities. \\
& C4.S3 & I worked with students I don't usually work with during the workshop. \\
& C4.S5 & Some students didn't let me do things the way I wanted. \\
& C4.S6 & I enjoyed all of the challenges we resolved as a group. \\
& C4.S7 & My group aided me in understanding the workshop's concepts. \\
\hline \multirow{5}{*}{ C5. } & C5.S1 & I received clear instructions for carrying out my tasks. \\
Facilitator's & C5.S2 & I received help from the facilitator whenever I needed it. \\
Role & C5.S3 & I gladly participated during the workshop because the facilitator asked us to. \\
& C5.S5 & The facilitator encouraged us to participate in the session and make the most of it. \\
& Boys and girls participated equally and received equal treatment from the facilitator. \\
& C5.S7 & The facilitator made us participate at all times during the activity. \\
& The facilitator did not address doubts that came up during the activity. \\
\hline
\end{tabular}

Table 3. Workshop assessment questionnaire $(\mathrm{C}=$ category, $\mathrm{S}=$ statement $)$

Some of these categories, as well as some of the statements they contained, were crafted following the method proposed by Hugerat (2016). However, they were adapted to the objectives and challenges of this research and to the evaluation of design methodologies for teaching science instead of the evaluation of project-based education. The questionnaire was given to the students one month after the workshop to assess if, after some time, they had retained the knowledge they had been taught.

The three teachers who took turns in assisting the facilitator during the activity also added their input to the workshop assessment questionnaire. They were asked to give a score of 1 to 4 for each category as a whole and write down any comments they deemed relevant.

\section{Results}

Nine maps filled out by the students were produced as a physical result of the session (Figure 3).
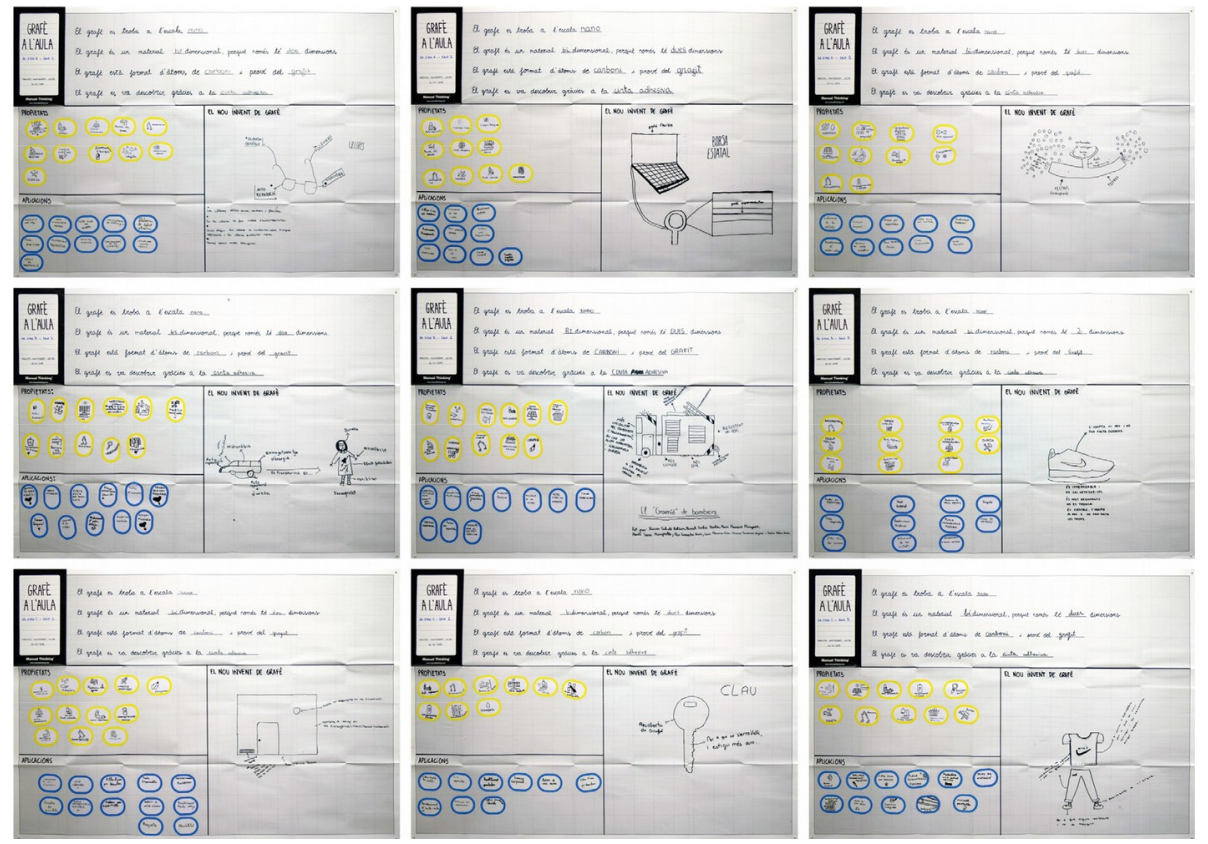

Figure 3. Maps filled out by students

Figure 4 shows the general assessment of the workshop by the teachers. As shown in the figure, all categories were given a score of 3 or 4 out of 4 . 


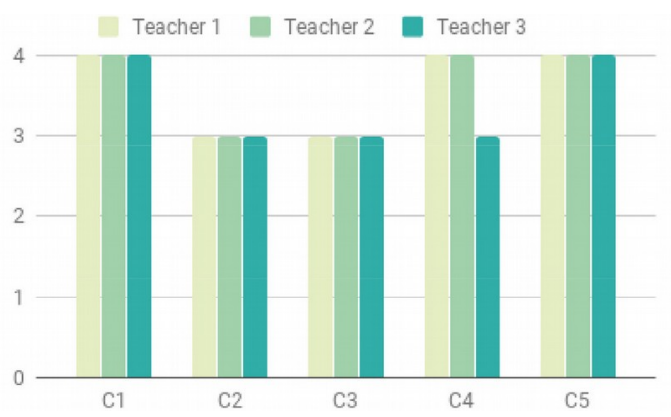

Figure 4. Quantitative results from the questionnaire answered by the teachers. Table 3 shows the coding of the five categories

The main findings from the questionnaires are given below, distributed into subsections for the five categories analyzed. In addition, qualitative comments from the teachers have been added. In the graphs shown throughout the section, " $\mathrm{A}$ " represents the most positive/favorable score and "D" the most negative/unfavorable score.

\subsection{Acquiring Knowledge}

As seen in Figure 4, the three teachers rated Acquiring Knowledge with the highest score. They emphasized in their comments that the presentation and knowledge transfer about graphene was excellent. They also stressed that they, as teachers, learned as much as or more than the students. On the one hand, they gained new knowledge about graphene and, on the other, they found the work methodologies inspiring for their classes. One of the teachers noted that the methodologies used worked on different types of intelligence in a way that students with different abilities could understand the session's content more easily than in a traditional classroom format.

They also appreciated that the content in the session was new, as it made the session very interesting. The teachers positively assessed the initial theoretical foundations, the fact that the activities were well-planned, and the interaction with the students as three key factors in the transfer of knowledge.

In the student assessment (Figure 5), $42.6 \%$ of the students rated this category very positively. 39.1\% rated it second, $14.4 \%$ third, and only $3.9 \%$ the most negative. The two most favorable aspects for the students were that they learned a lot about graphene and nanomaterials and that the information was suitably adapted to their level. A negative point worth noting is that, after some time, they did not remember most things that had been taught.

(a)

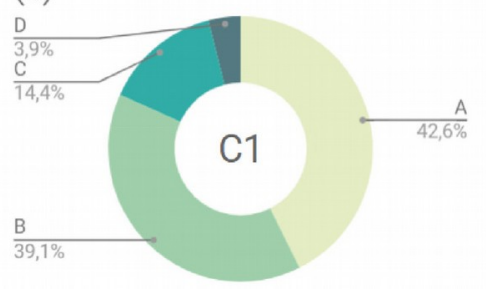

(b)

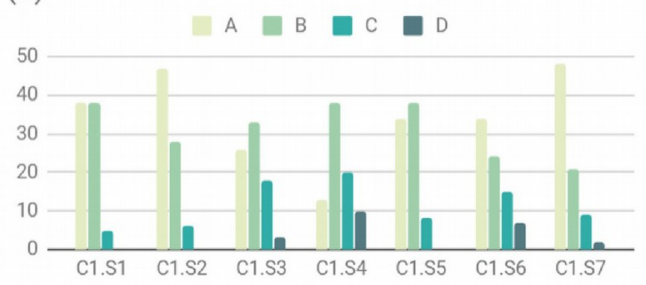

Figure 5. Student assessment of category C1. Acquiring Knowledge (a) as a whole and (b) for each question. Table 3 shows the coding of the statements

\subsection{Satisfaction}

Regarding Satisfaction, the teachers positively rated the autonomy of the students and that they motivated themselves and adapted their energy and dedication to what each activity required. One of the teachers noted that "[t]he students expressed great satisfaction with the workshop and that the format was quite stimulating." The teachers were also pleased with the fact that it was a dynamic activity in which students had to be active and willing to participate. They highlighted that, in the traditional classroom format, students are much more passive and, in some cases, detached. 
Two of the teachers said that one of the challenges schools face is knowing how to handle interactive activities in contexts that are not yet adapted to them. Additionally, one of the teachers noted that " $[\mathrm{t}] \mathrm{he}$ lack of preconceived notions (knowledge of graphene and design methodologies) generates student interest but, at the same time, a sort of relaxation as the students associate games with playful environments, not learning."

$58.3 \%$ of students gave the highest score in the Satisfaction category (Figure 6). The most valued aspects were satisfaction with their own attitude, satisfaction with the fact that the facilitator was happy with the work they did, and satisfaction with the workshop's format, which made the students enjoy the activity more than a normal class. Conversely, some students thought that the activity was too long and some did not enjoy all the activities, but some more than others.
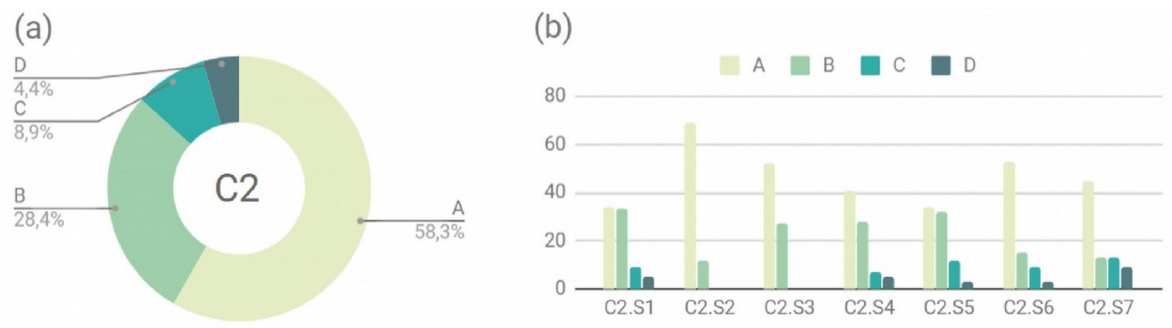

Figure 6. Student assessment of category C2. Satisfaction (a) as a whole and

(b) for each question. Table 3 shows the coding of the statements

\subsection{Challenges}

In the Challenges category, the teachers pointed out that they found some challenges in carrying out the workshop activities. In terms of participation, content comprehension, and concentration, the students responded quite favorably as the format was very appropriate, according to one of the teachers. However, the main challenge the teachers encountered in the activities was the size of the groups. All three indicated that it would have been better to have smaller groups, between 6 to 8 students. Done this way, participation and involvement by all students would increase.

Another challenge that was noted was the same as discussed in the previous category (Satisfaction). In the words of one teacher: "[a]ny activity that involves breaking down the typical classroom structure - with its unidirectional nature in which knowledge is centered on the teacher - makes the students more relaxed." Simultaneously, such relaxation implies noise and distractions. Handling possible distractions is key for dynamic activities in which students are at the center.

As shown in Figure 7, 65.1\% of students found no challenges in carrying out the workshop tasks, while $6.5 \%$ found many. All questions in this category were assessed quite favorably. It should be noted that the most positive was that there was no gender discrimination during the workshop. In contrast, the most negative was that it was difficult for some students to understand what the facilitator expected at certain times. In this category, however, student satisfaction with the workshop as a whole is once again manifest.

(a)

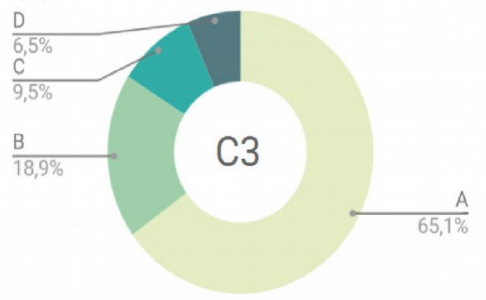

(b)

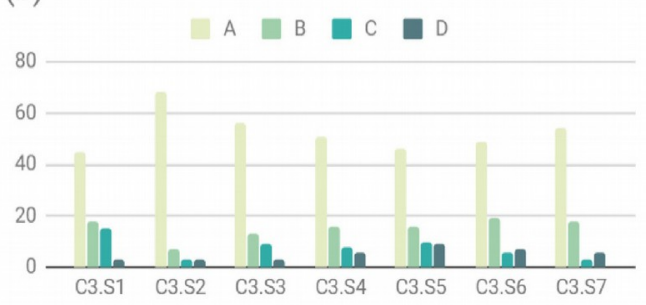

Figure 7. Student assessment of category C3. Challenges (a) as a whole and

(b) for each question. Table 3 shows the coding of the statements 


\subsection{Teamwork}

When assessing Teamwork, all three teachers defined the workshop as inclusive since students with learning difficulties participated in almost the same way as the rest of their classmates. As one teacher stated, "[t]he workshop was very inclusive. One clear example is that a student with special learning needs went up to the board for the Transfer and Guess activity to draw one of the graphene properties, and the student's teammates guessed it. This was the first time I have seen this student going up to the board and not just that, the student did the task as well as any other."

Regarding the format of the activities and the interaction between classmates, the teachers thought that "the balance of competition/cooperation was quite appropriate and did not create situations that would harm relationships between students." They also noted that " $[\mathrm{t}] \mathrm{he}$ teamwork was genuine, everyone participated, and having students with different abilities and levels of understanding was not a problem."

Other statements commented on the workshop's tools and methodology, such as: "[d]uring the session, we learned and verified that gamification is a good democratizing tool" and "[c]ompetition is innate, but our school does not promote it that much. These kinds of activities, which combine competition with cooperation, help encourage the positive side of competition." An important point to note here is that the groups were thought out and organized by the teachers. This made the groups balanced in terms of roles, participation, motivation, and collaboration.

There is a great diversity of opinion by the students in this category (Figure 8). $45.8 \%$ rated Teamwork highly, $24.3 \%$ good, $16.7 \%$ fair, and $13.3 \%$ poor. The most positive aspects were related to good relationships with teammates, competing in certain activities, and the fact of facing all the challenges as a group. In contrast, the most negative aspects revealed that some group members did not want to participate in the activities and that students did not help each other within the teams to understand complex concepts, which always fell on the facilitator or assisting teacher to help.

(a)

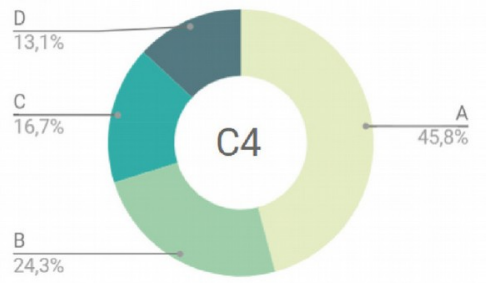

(b)

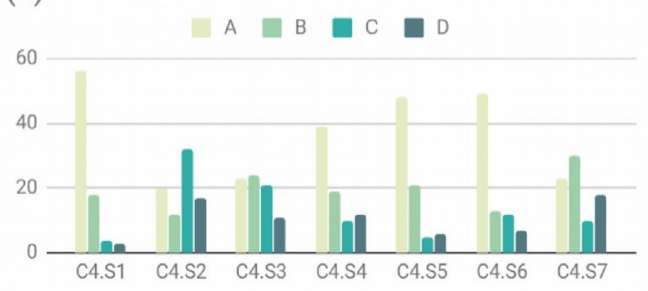

Figure 8. Student assessment of category C4. Teamwork (a) as a whole and

(b) for each question. Table 3 shows the coding of the statements

\subsection{Facilitator's Role}

Regarding the Facilitator's Role, the teachers noted the importance of the facilitator's tone and capacity for empathy and motivation, and all three agreed that the facilitator did an excellent job. "Clear, thorough technical information presented in a pleasant and age-friendly manner without the facilitator being too much a part of everything yet providing all terms," said one of the teachers.

There was a diversity of opinion regarding the fact that the facilitator was not a staff member at the school. One teacher did not think it was too relevant that the workshop's facilitator was not a staff member, while another emphasized that an external facilitator "gave more identity and value to the workshop." The third teacher did not comment on this aspect.

The students assessed the Facilitator's Role highly (Figure 9). 62.2\% of students gave the most favorable score, and only $4.6 \%$ the most unfavorable. Among the most positive aspects, clear instructions, help offered, motivation, approachable and fair treatment, and addressing doubts are most noteworthy. 
(a)

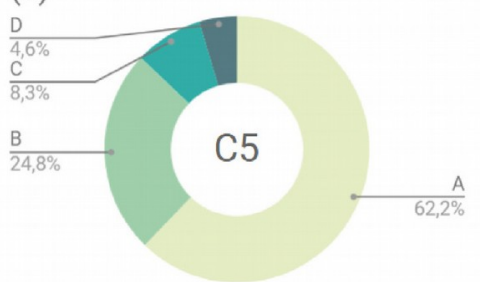

(b)

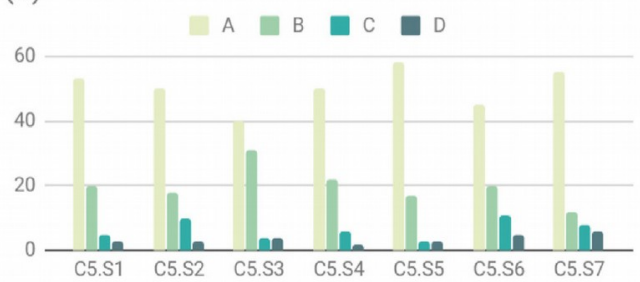

Figure 9. Student assessment of category C5. Facilitator's Role (a) as a whole and (b) for each question. Table 3 shows the coding of the statements

\subsection{Observation notes}

Most observations made by the teachers were included in the questionnaires. However, some comments not included in any of the above categories were also given. The three most relevant issues noted were the following:

Most students had a hard time understanding the relationship between design methodologies and learning about a scientific subject such as graphene. They did not understand why bringing these two disciplines together was desirable.

While doing the Formulate activity, the students began to draw their product proposals on different booklets or sheets. The reason for doing so was that they wanted the final drawing to be aesthetically pleasing, which is why they started with a rough draft then cleaned it up for the work map.

Relationships and social interaction were enhanced thanks to the different activities in the workshop. Students felt listened to and appreciated at all times all while interacting with one another positively and naturally at the same time.

\section{Discussion and Conclusions}

The "Graphene in the Classroom" workshop turned out satisfactorily in many respects. The experimental educational toolkit obtained a highly positive assessment in the Acquiring Knowledge category (Figures 4 and 5). According to the teachers' assessment, not only knowledge about graphene was gained during the session, but also new learning methods and techniques. Furthermore, the initial theoretical foundations were positively assessed, as well as the change in pace between activities and the time spent on them.

For the development of the activity, we took into account that a favorable emotional climate in the classroom enhances students' personal growth (Carroll et al., 2010; Scheer et al., 2012) and that a student-focused educational system can increase motivation for learning (Broussard \& Garrison, 2004; Pratt, 2002). The fact that overall student Satisfaction with the workshop was high (Figure 6) shows that the climate that was created was pleasant and motivating.

However, we see a contrast between this view compared to the teachers' assessment (Figure 4). The teachers positively assessed the autonomy and self-motivation of the students, but also noted three negative aspects. First, the fact that they did not know how to handle an activity of this nature due to lack of experience or habit. In this sense, the facilitator's presence was key. Second, the flexibility of the space was also mentioned as the activity was held in a traditional classroom and, despite reorganizing the tables, the regular unidirectional classroom format makes the spaces not quite suitable for dynamic activities. As several authors attest, designing a flexible space facilitates learning, autonomy, inclusion, and interaction, among others (Hadim \& Esche, 2002; Kariippanon et al., 2018). Finally, the fact that the students were not accustomed to this type of workshop meant that there was a sort of relaxation or playful atmosphere in the classroom at certain times.

Said relaxation was also a challenge, since it sometimes involved noise and distractions. Teachers attributed this to the size of the groups. However, some authors associate this challenge with a benefit: the reduction of tension in the classroom (Hugerat, 2016). By focusing the activity on the students, tension in the environment is reduced and this creates a much more relaxed classroom climate. From the point of view 
of the students (Figure 7), few Challenges were noted. Those that stood out were related to how it was difficult to understand what was expected of them in certain activities. This relates to how many students had a hard time understanding the relationship between design methodologies and learning about science.

The Teamwork assessment (Figure 8) also reveals that the most significant challenge noted both by students and by teachers is the difficulty of adapting a traditional classroom format to a dynamic format such as a workshop. Learning by doing has many benefits (Dewey, 1902; Scheer et al., 2012). However, much remains to be done before schools can integrate this into their daily operations. One observation that proves this is the fact that the students began to draw their proposals as a rough draft before cleaning them up and making a final drawing. Design methodologies do not focus on aesthetic or formal perfection, but on the search for solutions. Habits and approaches like this are deeply entrenched in schools, and changing them would imply a paradigm shift.

Regarding the Facilitator's Role, the most valued characteristics were empathy, motivation, clear explanations, scientific rigor, and the adaptation of contents (Figure 9). As Lumpkin (2007) affirms, a student's motivation and predisposition depend, to a large extent, on the facilitator's support and presence. This activity pursued a balance between an objective and thorough explanation about a complex subject and supporting the students in their learning process. As such, the teachers assessed the activity using the words inclusion, integration, and interaction.

Designing a workshop that integrates academic standards, theoretical content, and design methodologies is a complex process, challenging in many respects. However, design methodologies allow translating complex languages into friendlier, more approachable, and easier language (Guasch et al., 2019). As such, design methodologies are also included in social environments and encourage problem resolution based on creative thinking and the development of innovative strategies (Curedale, 2016; Design United, 2013; Hanington \& Martin, 2012; Leblanc, 2016).

The methodologies used in this workshop are a just small sample of the wide array of methods, resources, materials, and techniques that the design discipline can offer in science and technology education. The students who took part in the "Graphene in the Classroom" workshop served as an example to test whether these types of activities work in a school setting. The results were quite favorable and, for this reason, we believe that design methodologies are a good resource and can help simplify more complex languages and transfer knowledge. However, the specific methodologies used are not the only ones available, just as graphene and nanomaterials are not the only scientific topics that can be communicated through them. We offer this model as an example and a guide to continue researching how to apply design methodologies to scientific communication and education.

\section{Declaration of Conflicting Interests}

The authors declared no potential conflicts of interest with respect to the research, authorship, and/or publication of this article.

\section{Funding}

The authors received no financial support for the research, authorship, and/or publication of this article.

\section{References}

Broussard, S.C., \& Garrison, M.E. (2004). The relationship between classroom motivation and academic achievement in elementary school-aged children. Family and Consumer Sciences Research Journal, 33(2), 106-120. https://doi.org/10.1177/1077727X04269573

Carroll, M., Goldman, S., Britos, L., \& Koh, J. (2010). Destination, Imagination and the Fires Within: Design Thinking in a Middle School Classroom. The Journal of Academic Development and Education, 29(1), 37-53. https://doi.org/10.1111/j.1476-8070.2010.01632.x

Correia, A., \& Serena-Domingo, P.A. (2010). 2010-2020: ¿La década del despegue de la nanotecnología española? [2010-2020: The decade of the takeoff of Spanish nanotechnology?] Física y Sociedad, 36-39. 
Curedale, R.A. (2016). Design Thinking Process \& Methods Guide (3rd ed.). Topanga CA: Design Community College Inc.

de Bono, E. (1994). Creative Thinking. The Power of Lateral Thinking for the Creation of New Ideas. Paidós.

Design United. (2013). Advanced Design Methods for Successful Innovation. Ministry of Economic Affairs.

Dewey, J. (1902). The child and the curriculum. Chicago: University of Chicago Press.

Dignan, A. (2011). Game Frame: Using Games as a Strategy for Success. New York: Free Press.

Dorst, K. (2011). The core of "design thinking” and its application. Design Studies, 32(6), 521-532. https://doi.org/10.1016/j.destud.2011.07.006

European Commission. (2012). Communicating EU Research and Innovation: A Guide for Project Participants. Available at: http://ec.europa.eu/research/participants/portal/ShowDoc/Extensions+Repository/

Ferrari, A.C., Bonaccorso, F., Falko, V., Novoselov, K.S., Roche, S., Bøggild, P., et al. (2015). Science and technology roadmap for graphene, related two-dimensional crystals, and hybrid systems. Nanoscale, 7(11), 4598-4810. https://doi.org/10.1039/C4NR01600A

Guasch, B., Cortiñas, S., González, M., \& Peña, J. (2019). Design Methodologies for Bridging Science, Technology, and Industry: A Graphene-Centered Case Study. The International Journal of Design Management and Professional Practice, 13(1). https://doi.org/10.18848/2325-162X/CGP/v13i01/1-20

Hadim, H.A., \& Esche, S.K. (2002). Enhancing the engineering curriculum through project-based learning. In Frontiers in Education Conference, 1-6. Boston. https://doi.org/10.1109/FIE.2002.1158200

Hanington, B., \& Martin, B. (2012). Universal Methods of Design. Beverly, MA: Rockport Publishers.

Hirsch, A. (2015). The Graphene Flagship - A Giant European Research Project. Angewandte Chemie International Edition, 54(32), 9132-9133. https://doi.org/10.1002/anie.201504842

Hugerat, M. (2016). How teaching science using project-based learning strategies affects the classroom learning environment. Learning Environments Research, 19(3), 383-395. https://doi.org/10.1007/s10984-016-9212-y

Kariippanon, K.E., Cliff, D.P., Lancaster, S.L., Okely, A.D., \& Parrish, A.M. (2018). Perceived interplay between flexible learning spaces and teaching, learning and student wellbeing. Learning Environments Research, 21(3), 301-320. https://doi.org/10.1007/s10984-017-9254-9

Leblanc, T. (2016). Research-driven Design: The Case of Repurposing Glass. The International Journal of Design in Society, 10(3), 31-40. https://doi.org/10.18848/2325-1328/CGP/v10i03/31-40

Lenschow, R.J. (1998). From teaching to learning: A paradigm shift in engineering education and lifelong learning. European Journal of Engineering Education, 23(2), 155-161.

https://doi.org/10.1080/03043799808923494

Lumpkin, A. (2007). Caring teachers: The key to student learning. Kappa Delta Pi Record, 43(4), 158-160. https://doi.org/10.1080/00228958.2007.10516474

Mertens, R. (2018). The Graphene Handbook. https://www.lulu.com/

Novoselov, K.S., Geim, A.K., Morozov, S.V., Jiang, D., Zhang, Y., Dubonos, S.V., et al. (2004). Electric Field Effect in Atomically Thin Carbon Films. Science, 306(5696), 666-669.

https://doi.org/10.1126/science.1102896

Pratt, D. (2002). Analyzing perspectives: Identifying commitments and belief structures. In Five perspectives on teaching in adult and higher education (217-255). Malabar, FL: Krieger Publishing Company.

Raijmakers, B., Thompson, M., \& Van de Garde-Perik, E. (2012). New goals for design, new roles for designers? Helsinki: Cumulus.

Romero, C., Cazorla, M., \& Buzón, O. (2017). Meaningful learning using concept maps as a learning strategy. Journal of Technology and Science Education, 7(3), 313-332. https://doi.org/10.3926/jotse.276 
Sanders, E.B.N., \& Stappers, P.J. (2008). Co-creation and the new landscapes of design. CoDesign, 4(1). https://doi.org/10.1080/15710880701875068

Scheer, A., Noweski, C., \& Meinel, C. (2012). Transforming constructivist learning into action: Design thinking in education. Design and Technology Education: An International Journal, 17(3), 8-19. https://doi.org/10.1007/BF02019079

Spinuzzi, C. (2005). The Methodology of Participatory Design. Technical Communication, 52(2), 163-174.

Valdez, J., \& Bungihan, M. (2019). Problem-based learning approach enhances the problem solving skills in chemistry of high school students. Journal of Technology and Science Education, 9(3), 282-294.

https://doi.org/10.3926/jotse.631

\author{
Published by OmniaScience (www.omniascience.com) \\ Journal of Technology and Science Education, 2020 (www.jotse.org)
}

\title{
(c) $(1)(8)$
}

Article's contents are provided on an Attribution-Non Commercial 4.0 Creative commons International License. Readers are allowed to copy, distribute and communicate article's contents, provided the author's and JOTSE journal's names are included. It must not be used for commercial purposes. To see the complete licence contents, please visit https://creativecommons.org/licenses/by-nc/4.0/. 